\title{
Le regard des professionnels
}

